\title{
PENGENALAN AEROMODELLING BERBASIS IT UNTUK MENUMBUHKAN JIWA WIRAUSAHA DAN PRESTASI DI SMK NU TARUB TEGAL
}

\author{
Jatmiko Indriyanto ${ }^{1)^{*}}$, Wildani Eko Nugroho ${ }^{2)}$, Nurohim ${ }^{3)}$ \\ ${ }^{123}$ D3 Teknik Komputer, Politeknik Harapan Bersama Tegal \\ *Email: dewajat@gmail.com
}

\begin{abstract}
Abstrak
Permasalahan mendasar dari lulusan SMK adalah sebagian besar masih mencari kerja pada perusahaan, karena banyaknya lulusan SMK tidak sebanding dengan lapangan kerja yang ada di perusahaan, sehingga banyak yang menganggur. Pengangguran terbuka pada jenjang lulusan SMK masih tinggi. Hasil analisis potensi ekonomi atas data pengangguran terbuka pada tahun 2015 menunjukkan sepertiga lebih atau 36,78\% lulusan SMK masih menganggur.Masih banyak mental mencari kerja, bukan mental menciptakan usaha, membangun bisnis. Belum maksimalnya pendidikan dan pelatihan bagi pencari kerja yang diselenggarakan Pemerintah Kota Tegal untuk mendorong mereka menjadi wirausaha baru(WUB). Masih banyak siswa SMK yang kesulitan masuk ke perguruan tinggi negri karena kurangnya prestasi.Pemerintah sudah menyediakan jalur prestasi, yang proses seleksinya berfokus pada prestasi-prestasi dalam akademis maupun non akademis selama masa SMA/sederajat Melihat masalah diatas, maka Pengenalan Aeromodelling Berbasis IT Untuk Menumbuhkan Jiwa Wirausaha dan Prestasi, dapat meningkatkan minat siswa untuk beralih pikirannya untuk mencoba wirausaha dan prestasi. Pengenalan Aeromodelling Berbasis IT Untuk Menumbuhkan Jiwa Wirausaha dan Prestasi ternyata dapat, meningkatkan minat siswa untuk berwirausaha dan berprestasi dalam bidang non akademik.
\end{abstract}

Kata kunci: SMK, wirausaha, prestasi, aeromodelling

\begin{abstract}
The basic problem of SMK graduates is that most are still looking for work in companies, because the number of SMK graduates is not comparable to the employment opportunities in companies, so many are unemployed. Unemployment is open at the level of SMK graduates is still high. The results of an analysis of the economic potential of the open unemployment data in 2015 showed that over one third or $36.78 \%$ of vocational school graduates were still unemployed. Education and training for job seekers has not been maximally organized by the Tegal City Government to encourage them to become new entrepreneurs (WUB). There are still many vocational students who have difficulty getting into state universities because of lack of achievement. The government has provided a path of achievement, the selection process focuses on academic and non-academic achievements during high school / equivalent Seeing the above problems, the introduction of IT-based Aeromodelling to Grow Entrepreneurial Soul and Achievement, can increase student interest to switch his mind to try entrepreneurship and achievement. The introduction of IT-based Aeromodelling for Growing an Entrepreneurial Soul and Achievement turned out to be able to, increase students' interest in entrepreneurship and achievement in non-academic fields.
\end{abstract}

Keywords: SMK, entrepreneurship, achievement, aeromodelling 


\section{PENDAHULUAN}

Seiring perkembangan teknologi informasi yang sangat pesat maka proses pembelajaran dapat dilakukan lebih baik, dengan mengimplementasikan teknologi dalam pengajaran. Proses Pembelajaran dengan tatap muka adalah proses pembelajaran yang sering dilakukan oleh para pengajar, tetapi ada kalanya siswa juga dituntut untuk aktif dalam proses pembelajaran atau biasa disebut Student Center Learning atau biasa disingkat dengan SCL. Dengan perkembangan teknologi yang sangat cepat maka internet menjadi hal yang sangat penting bagi kehidupan manusia.

Memasuki era milenia, gadget sudah bukan barang mewah lagi tetapi menjadi kebutuhan yang menunjang kehidupan manusia di segala bidang, yang biasa dikenal dengan istilah Internet of Things(IoT) yakni benda-benda atau alat alat yang cerdas yang dapat berguna untuk kehidupan manusia. SMK NU Hasyim Ashari Tegal merupakan sekolah menengah atas yang memiliki salah satu visinya adalah mencetak peserta didik berIPTEK yang berlandaskan IMTAQ Kreatif, mandiri dan siap kerja serta cinta dan peduli terhadap Bangsa dan Negara sehingga dalam pembelajarannya selain siswa dibekali oleh keteampilan hardskill juga dibekali dengan softskill. Untuk tercapainya visi tersebut maka proses pembelajaran pada SMK NU Hasyim Ashari Tegal memegang peranan yang penting. Siswa harus dapat memiliki hardskill dan softskill karena diharapkan setelah lulus akan menjadi sumber daya manusia yang memiliki daya saing tinggi untuk melanjutkan ke jenjang pendidikan yang lebih tinggi walaupun tidak menutup kemungkinan bagi lulusannya untuk memasuki dunia kerja. Oleh karena itulah Softskill sangat dibutuhkan agar lulusannya memenuhi persyaratan bagi stakeholder.

SMK NU Hasyim Ashari adalah Sekolah Menengah Kejuruan yang berlokasi di Jl. Karangjati Kabupaten Tegal, Jawa Tengah 52125, merupakan salah satu SMK Swasta berbasis dengan jumlah siswa kelas $10,11, \& 12$ sekitar 870 siswa karena lulusannya selain dibekali ilmu agama yang lebih juga dibekali hardskill dan softskill tentang ilmu teknologi Komputer Sesuai dengan Visi SMK NU Hasyim Ashari Tegal, Menjadikan SMK NU Hasyim Ashari Kabupaten Tegal sebagai lembaga pendidikan dan pelatihan atau pembelajaran yang professional dan mandiri dalam mewujudkan SMK Center of Excellence melalui sikap disiplin, jujur, kerja keras dan kreatif.

Lulusan SMK NU Hasyim Ashari kebanyakan menginginkan bekerja diperusahaan atau di tempat usaha orang lain, padahal lulusan dari SMK yang mempunyai jurusan yang sama, sudah banyak sekali, sehingga kesulitan mencari pekerjaan, maka dari itu dengan adanya pengenalan aeromodelling untuk menumbuhkan jiwa wirausaha, diharapkan setelah bisa membuat pesawat aeromodelling, bisa membuka wirausaha, tanpa tergantung kepada orang lain.

\section{METODE PELAKSANAAN}

Kegiatan berupa penyampaian materi teori pengenalan aeromodelling dan praktek berupa menampilkan pesawat aeromodelling dan cara pembuatannya. Selama pengenalan aeromodelling ini didampingi oleh seorang dosen dan perwakilan dari PORDIRGA kota Tegal secara interaktif.

Materi yang disajikan antara lain:

1. Pengenalan Aeromodelling

2. Kegunaan Aeromodelling

3. Aeromodelling untuk prestasi

4. Pembuat pesawat aeromodelling untuk wirausaha

Untuk pembuatan pesawat aeromodelling untuk wirausaha, diajarkan tahap-tahap pembuatan pesawat, yang dimulai dengan, 1. Planing, 2. Building, 3. Testing, 4. Flying.

Tempat pelaksanaan : SMK NU Tarub Tegal Waktu pelaksanaan : 16 s/d 17 Februari 2020

\section{HASIL DAN PEMBAHASAN}

Dalam pengenalan aeromodelling yang disampaikan antara lain, pengertian aeromodelling, definisi umum, cabang aeromodelling, keuntungan aeromodelling, nomor lomba aeromodelling. Aeromodelling adalah suatu kegiatan yang menggunakan sarana miniatur (model) pesawat 
terbang(Yanda \& Rahmawaty, 2015). Dalam kegunaan aeromodelling disampaikan kelebihan aeromodelling untuk olahraga dan hobby. Untuk aeromodelling prestasi, diperlihatkan prestasi yang sudah didapat atlet aeromodelling kota Tegal, sudah pernah berprestasi di Porprov Jateng pada tahun 2018, siswa yang berminat diarahkan untuk ikut dan melihat latihan yang biasa diadakan oleh klub BAC(Bahari Aero Club) di GOR Tegal Selatan. Dalam pengenalan siswa juga dijelaskan mengenai aerial photographs, aerial photographs menggunakan dji phantom dapat menghasilkan gambar photo yang menarik(Suroso \& Pratama, 2020), yang bisa untuk wirausaha.

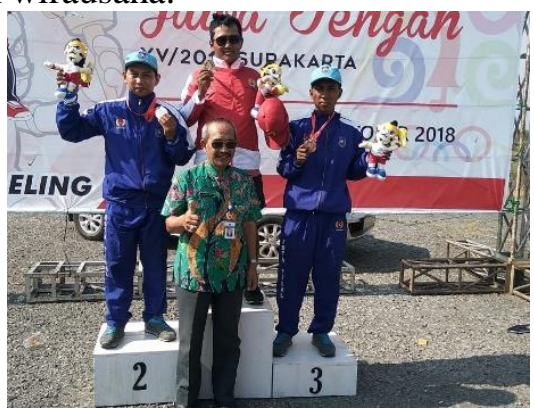

Gambar 1. Prestasi dalam aeromodelling

Kegiatan yang dilakukan dalam pembuatan pesawatan untuk wirausaha, dalam planning siswa mulai menggambar pola pesawat di kertas, kemudian diletakkan di polyfoam, dan digunting sesuai pola. Pembuatan sayap harus benar, agar menghasilkan gaya-gaya tersebut agar pesawat dapat terbang(Miraza \& Isranuri, 2012)

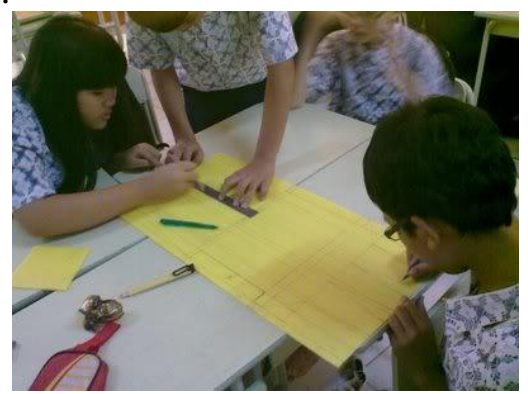

Gambar 2. Siswa mulai membuat planning

Pada bagian building, siswa mulai membuat pesawat, dengan menyatukan bagian-bagiannya dengan menggunakan lem cina, masangnya harus presisi, jika tidak, pas terbangnya bisa jatuh. Juga memasang bagian-bagian pesawat yang terpisah, dijadikan satu dengan bodynya. Sebuah pesawat yang telah dioptimalkan pembuatannya dengan hati-hati untuk kondisi penerbangan tunggal akan cenderung berkinerja buruk di kondisi penerbangan lainnya, pada awalnya terbangnya bagus(Fincham \& Friswell, 2015).

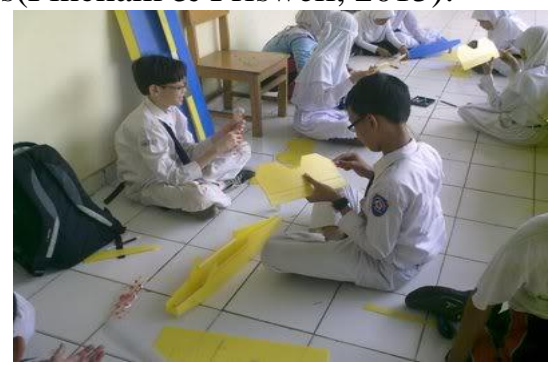

Gambar 3. Siswa mulai membuat planning

Pada bagian testing, semua pesawat dicoba aleiron dan fuselagenya. Dicoba juga untuk menerbangkan selama beberapa menit atau $1 / 2$ jam, untuk mengecek kestabilan pesawat saat terbang.

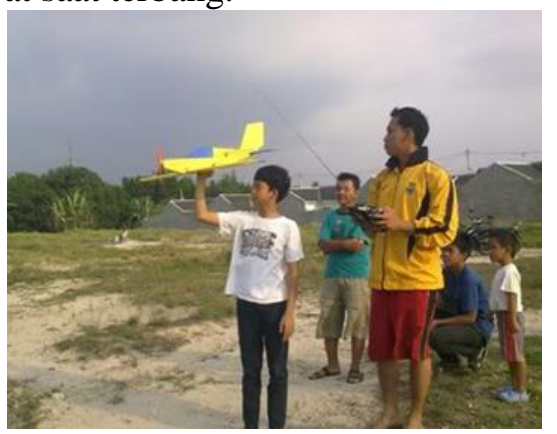

Gambar 4. Mencoba pesawat

Pada bagian flying, pesawat diterbangkan kembali setelah batre discharge, untuk melatih siswa agar bisa menerbangkan, biasanya dicoba berulang-ulang, sampe $3 \mathrm{kali}$ atau 4 kali.

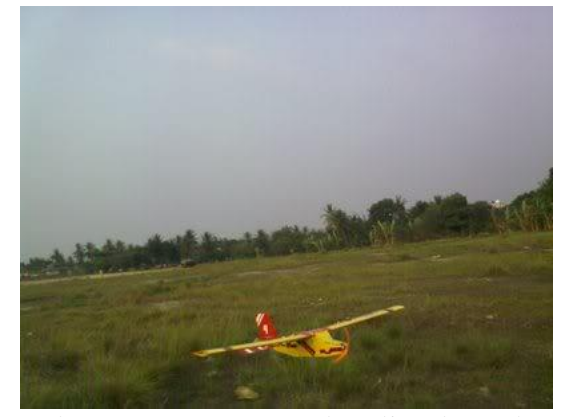

Gambar 5. Pesawat coba diterbangkan

Pada bagian flying siswa diajarkan mengendalikan pesawat dengan benar, juga dibiasakan adaptasi dengan menerbangkan pesawat berkali-kali, agar mengetahui jika ada kekurangan dalam pesawatnya. Jika bisa 
mengetahui ada kekurangan dalam pesawatnya, bisa menghindari pesawat jatuh. Siswa bisa mengetahui gaya aerodinamika sehingga bisa terbang mulus secara alami(Lubis, Isranuri, and Belakang 2012). pada saat menerbangkan pesawat tanpa awak harus memperhatikan 3 parameter, parameter gaya, kecepatan, dan orientasi(Majid, Sumiharto, and Wibisono 2015). Kestabilan dan manuver pesawat juga dipengaruhi oleh $\mathrm{CG}$ (Center of Gravity)(Hidayat and Mardiyanto 2017).

Siswa juga diajarkan penggunaan simulator pesawat menggunakan computer dan remote pesawat, dengan tujuan bisa latihan mengendalikan pesawat, sebelum menerbangkan pesawat yang sesungguhnya. Mengapa kita membuat pesawat fixed wing untuk siswa, karena pesawat fixed wing mudah dikendalikan dan diterbangkan(Suroso and Irmawan 2018).

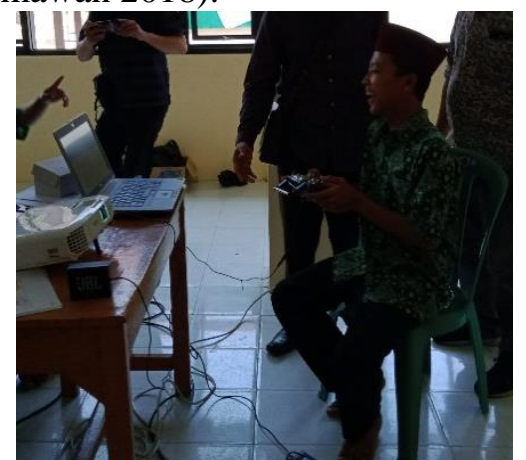

Gambar 6. Siswa mencoba simulator

Pada gambar diatas, siswa mencoba simulator, diajarkan bisa menerbangkan dan menurunkan pesawat hingga lancar. keefektifan pelatihan ini tergantung dalam beberapa hal, pertama oleh si pengisi materi dalam menguasai apa yang disampaikan, kelengkapan alat untuk mendukung persentasi dan praktek, pengisi materi untuk berhasil membuat siswa untuk tertarik mencoba dan tertarik untuk mengikuti. Berdasarkan hasil analisis uji pretest dan posttest yang dilakukan terhadap 68 siswa yang mengikuti pelatihan, terdapat hasil nilai sig(2-tailed) $=$ 0.018 dengan taraf signifikansi 0,000 $(\mathrm{p}<0,05)$ skor rerata pretest 68,72 menjadi nilai rerata posttest 110,56 . Perbedaan angka pretest dan posttest memperlihatkan adanya perubahan substansial pada tingkat penangkapan dan kompetensi, untuk menggunakan aeromodelling sebagai wirausaha dan sarana mendapatkan prestasi.
Tabel 1. Pretest dan Posttest

\begin{tabular}{|l|r|r|r|}
\hline \multicolumn{1}{|c|}{ NamaSiswa } & Pretest & Posttest & Defference \\
\hline Eli Rahmawati & 40 & 60 & 20 \\
\hline Leni Mujiyati & 35 & 70 & 35 \\
\hline Siti Julekha & 39 & 65 & 26 \\
\hline Selfi Elfira & 31 & 80 & 49 \\
\hline Nurul Aisyah & 30 & 62 & 32 \\
\hline Nurul Aeni Alislah & 30 & 70 & 40 \\
\hline Dewi Wulandari & 42 & 68 & 26 \\
\hline Desi Rahmawati & 50 & 70 & 20 \\
\hline Dopir Jaka Sabarno & 32 & 70 & 38 \\
\hline Restu Irchami & 38 & 85 & 47 \\
\hline Riki Rudianto & 39 & 61 & 22 \\
\hline Donny Artavila & 44 & 60 & 16 \\
\hline M Ibnu Aryawan & 41 & 75 & 34 \\
\hline Zidan Rohmatullah & 55 & 72 & 17 \\
\hline Yahya Muhaemin & 42 & 73 & 31 \\
\hline Ahmad Hasanudin & 40 & 74 & 34 \\
\hline Mochaman Ruchi A & 40 & 77 & 37 \\
\hline Muhammad Ade Saputra & 41 & 80 & 39 \\
\hline Moh Nur Ardiansyah & 56 & 72 & 16 \\
\hline Moh Ma'ruf Hidayat & 38 & 73 & 35 \\
\hline Muh Aldi Hidayat T & 36 & 74 & 38 \\
\hline Ahmad Ainu Rofik & 46 & 67 & 21 \\
\hline 1
\end{tabular}

\section{KESIMPULAN}

Pelatihan pengenalan aeromodelling untuk prestasi dan wirausaha yang sudah dilaksanakan ternyata efektif dan berhasil untuk menarik minat siswa SMK Tegal untuk mencoba wirausaha dan prestasi dalam hal aeromodelling.

\section{REFERENSI}

Arifin fauzi lubis, i. I. 2012. Analisa gaya impak yang terjadi pada badan pesawat aeromodelling tipe glider saat landing dengan variasi sudut pendaratan yang disimulasikan dengan menggunakan software solidwork. E-dinamis, 62.

Fincham, J. H.S., and M. I. Friswell. 2015. "Aerodynamic Optimisation of a Camber Morphing Aerofoil." Aerospace Science and Technology 43: 245-55. http://dx.doi.org/10.1016/j.ast.2015.02.0 23.

Hidayat, Rahmad, and Ronny Mardiyanto. 2017. "Pengembangan Sistem Navigasi Otomatis Pada UAV (Unmanned Aerial Vehicle) Dengan GPS(Global Positioning System) Waypoint." Jurnal Teknik ITS 5(2).

Lisnawita. 2020. "Pelatihan Desain Grafis Untuk Meningkatkan Kreatifitas Siswa." Dinamisia: Jurnal Pengabdian Kepada Masyarakat 4(2): 231-35.

Lubis, Arifin Fauzi, Ikhwansyah Isranuri, and Latar Belakang. 2012. "Pesawat Aeromodelling Tipe Glider Saat Landing 
Disimulasikan Dengan Menggunakan Software Solidwork." Jurnal E-Dinamis I(1): 62-73.

“Majalah Peluang." 2020. 5 Maret 2020. http://majalahpeluang.com/aeromodellin g-kepiawaian-remote-control-orangdewasa/ (July 15, 2020).

Majid, Abdul, Raden Sumiharto, and Setyawan Bekti Wibisono. 2015. "Identifikasi Model Dari Pesawat Udara Tanpa Awak Sayap Tetap Jenis Bixler." IJEIS (Indonesian Journal of Electronics and Instrumentation Systems) 5(1): 43.

Mangkuprawira, S. 2004. Manajemen Sumber Daya Manusia Strategi. Jakarta Selatan: Ghalia Indonesia.

Miraza, Ricky Surya, and Ikhwansyah Isranuri. 2012. "Udara Dengan
Menggunakan Software Berbasis." $e$ Dinamis I(1): 0-10.

Suroso, Indreswari, and Erwhin Irmawan. 2018. "Analysis Of Aerial Photography With Drone Type Fixed Wing In Kotabaru, Lampung." Journal of Applied Geospatial Information 2(1): 102-7.

Suroso, Indreswari, and Hendriana Helda Pratama. 2020. "Analysis Mapping of Long Dry With Drone Type Dji Spark in Hargowilis , Kokap, Kulonprogo.” 4(1): 259-64.

Yanda, Jupri, and Made Rahmawaty. 2015. "Jurnal Politeknik Caltex Riau Perancangan Dan Implementasi Gerakan Hover Pada Tricopter.” 1(1): 34-43. 